\title{
The Interfaces Between Signal Transduction Pathways: IGF-1/ mTor, p53 and the Parkinson Disease Pathway
}

\author{
Arnold J. Levine ${ }^{1}$, Chris R. Harris ${ }^{1}$ and Anna M. Puzio-Kuter ${ }^{1}$ \\ ${ }^{1}$ Cancer Institute of New Jersey, UMDNJ, New Brunswick, N.J.
}

Correspondence to: Arnold J. Levine, email: alevine@ias.edu

Keywords: p53, parkinson disease, IGF-1, mTOR, RHEB

Received: November 20, 2012, Accepted: November 27, 2012, Published: November 28, 2012

Copyright: @ Levine et al. This is an open-access article distributed under the terms of the Creative Commons Attribution License, which permits unrestricted use, distribution, and reproduction in any medium, provided the original author and source are credited.

\section{Cell growth and division:}

The process of cell growth and division coordinates several input signals concerning the availability of nutrients in the environment of the cell. It then translates this information into intracellular activities that coordinate metabolic pathways to ensure sufficient energy sources, proper substrate concentrations and increased cell mass resulting in the production of two daughter cells. In the case of a single cell organism grown in culture, like yeast, the external glucose and amino acid concentrations are monitored. For multi-cellular organisms both glucose and amino acid concentrations are measured but in addition growth factors and cellular maintenance functions are monitored. This is accomplished by growth factor receptors that in turn initiate signal transduction pathways that regulate metabolic activity (IGF $-1 /$ mTor), and cell division (cell cycle regulators)[1-2]. These processes of cell growth and division require a high fidelity. A wide variety of stresses during cell division will lead to increases in error rates during DNA replication, DNA repair or chromosome segregation. One of the major responders (check points) to these types of stress (DNA damage, hypoxia, starvation for nutrients, etc) is the p53 pathway [2]. DNA damage is recognized by protein kinases such as ATM or ATR, which signal via phosphorylation to 553 and MDM-2, the ubiquitin ligase that promotes the degradation of p53 [3-4]. These rapid post-translational modifications inactivate MDM-2 and activate $\mathrm{p} 53$, which then promotes the transcription of selected genes. In this way p53 levels rise after cellular stresses. Stresses during the G-1 phase of the cell cycle are responded to by the $\mathrm{p} 53$ dependent transcription of the $\mathrm{p} 21$ gene [5]. The p21 protein binds to cyclin E-CDK-2 and inhibits it from stopping cell cycle progression in late G-1. Cells in the G-2/M phase of the cell cycle are blocked by p53 mediated transcription of 14-3-3 sigma which binds CDC-25c, keeping it in the cytoplasm and preventing this phosphatase from functioning in the cell nucleus
[4]. If these types of cellular damage are not repaired the activated p53 protein can initiate cellular death programs (often depending upon the cell type or whether the cells are cancerous or not) resulting in apoptosis or cellular senescence. The p53 inducible genes, Bax, Puma and Noxa act at the mitochondia to help release cytochrome c, which in turn interacts with the $\mathrm{p} 53$ regulated gene product APAF-1 to start a caspase cascade leading to apoptosis [6-8]. In this way p53 acts as a cell division check point, eliminating mistakes that can lead to abnormal cell division and cancers. But p53 has more subtle functions when it is activated.

\section{The antagonistic relationship between the p53 and the IGF-1/mTor pathways:}

The IGF-1 pathway is activated by the engagement of a wide variety of cellular tyrosine kinase growth receptors with their ligands. After dimerization of these receptors, phosphorylation and the binding of an adaptor protein, this complex attracts a PI3-kinase activity to the cellular membrane producing PIP-3 (phospho-inositol-3phosphate), a ligand that activates the TORC2 complex, which in turn phosphorylates and activates AKT-1. This kinase moves into the cell nucleus and phosphorylates the FOXO transcription factors which then exit from the nucleus turning on or off the transcription of a number of gene products that enhance cell growth and division [911] (figure 1). At the same time several cellular sensors are monitoring the external and internal concentrations of glucose and several amino acids. This information is delivered to the AMP kinase. Under conditions of glucose starvation lower levels of ATP are produced and the cellular AMP concentration rises. The alpha subunit of the AMP kinase binds this AMP, the beta subunit connects this complex to the gamma subunit which is then an activated protein kinase. One of the substrates of AMP kinase is the TSC-1 and TSC-2 protein complex and the phosphorylation of these proteins enhances a GTPase 
activity that converts GTP (active form) to GDP (inactive form) that is associated with the RHEB G-protein [12]. An active RHEB is required for an active TORC1 protein kinase (Figure 1). An inactive TORC1 (resulting from glucose starvation) starts the process of autophagy where cellular components are sequestered into cytoplasmic vesicles and degraded in the lysozome so as to supply substrates for maintenance of the cell during starvation conditions [1]. In the presence of ample glucose, TORC1 is active and phosphorylates two substrates, S-6 kinase and 4EBP that regulate cellular translation favoring cell growth and division [13-15] The AKT-1 kinase connects these two pathways by phosphorylating TSC-1 and TSC-2 and inactivating them (the GTPase), promoting cell growth [12]. Thus these two interacting pathways cooperate and insure the proper levels of substrates and growth signals leading to the metabolic contributions to cell division (figure 1).

The utilization of glucose by the metabolic pathways of the cell can itself be regulated [2]. Under normal rates of cell division (24 hour division times) in an aerobic environment, which maintains a steady state of new cells formed and old cells dying, glucose is taken up into the cell and passes through glycolysis and is efficiently converted from pyruvate to acetyl-CoA to be burned in oxidative phosphorylation to $\mathrm{CO}_{2}$ and $\mathrm{H}_{2} \mathrm{O}$ in the mitochondria. This produces the maximal levels of ATP per mole of glucose with the cleavage of all of the carbon bonds in glucose. Under conditions of very rapid cell division with a net increase in cell number, such as occurs in early embryogenesis (6 hour division times), during wound healing or when $\mathrm{T}$ or $\mathrm{B}$ cell clones are expanded during an immune response, glucose is metabolically processed differently. Glucose is rapidly run through glycolysis building up pyruvate, which in turn is converted to lactate and excreted from the cell lowering the levels of oxidative phosphorylation. This process generates much lower levels of ATP per mole of glucose and to make up for this lower energy efficiency about ten times the level of glucose is transported into the cell, through regulated glucose (GLUT) transporters, and sent through glycolysis and other pathways like the pentose phosphate shunt. While this now provides sufficient energy sources it also moves the carbons from glucose into high concentrations of substrates for fatty acids, amino acids and nucleic acids. Thus a rapid proliferation leading to increased cell numbers switches metabolic utilization of glucose to a pathway first described by Warburg for cancer cells and termed the Warburg effect [16-17]. Several cellular functions can contribute to this switch in metabolic processing of glucose (using either high aerobic glycolysis or oxidative phosphorylation) and these include both proto-oncogenes (myc, AKT) and HIF1 alpha favoring aerobic glycolysis. Several interacting tumor suppressor genes (PTEN, p53, TSC-1, TSC-2) favor oxidative phosphorylation [18-21]. This is why mutations in these genes often produce cancer cells with this altered metabolic pathway known as the Warburg effect (2).

When an activated $\mathrm{p} 53$ protein senses a stress that would interfere with normal progression through the cell cycle, it not only acts to stop cell cycle progression but it also shuts down the IGF-1 and mTor pathways $[1,22-$ 23] P53 mediated transcriptional activation of the PTEN gene produces the lipid phosphatase, PTEN, which degrades PIP-3 and the absence of PIP-3 inactivates AKT1 , TORC 1 and 2 shutting down both arms of this signal transduction pathway $[22,24]$. P53 also transcribes the TSC-2 gene enhancing the GTPase that inhibits TORC1 and it transcribes the gene encoding the AMP kinase beta subunit increasing its concentration [23]. The net effect of an enhanced transcription of these three genes is that an active p53 blocks the functioning of the IGF$1 /$ mTor pathways shutting down metabolic support for cell growth and division (figure 1). An activated p53 also promotes the use of oxidative phosphorylation and the complete burning of glucose, thus limiting substrates for cell division and antagonizing the Warburg effect. It does this by repressing transcription of Pdk2, the negative regulator of the pyruvate dehydrogenase complex, and thereby causes pyruvate to be converted into the TCA cycle substrate acetyl-CoA [25]. P53 also transcribes the $\mathrm{SCO} 2$ gene, which provides cytochrome c oxidase in complex 1 of the mitochrondria favoring oxidative phosphorylation [26]. P53 regulates the GLS-2 gene, which produces glutaminase-2 (GLS-2) that converts glutamine to glutamate and in the mitochondia provides more alpha-keto glutarate for the TCA cycle [27]. Finally p53 regulates the transcription of the Parkin gene, which also plays a role in slowing the Warburg effect [28].

\section{The role of reactive oxygen as a stressor in cell growth, division and death:}

One of the by-products of an active aerobic metabolic state is the formation of reactive oxygen species (ROS) such as peroxides. These reactive components are produced by lipoxygenases, NADPH oxidases and malfunctioning mitochrondria making errors in complex 1 oxidative phosphorylation. The production of ROS is damaging to a cell causing DNA breaks, oxidizing proteins and lipids and disrupting functions essential for cell maintenance, growth or division. Not surprisingly, ROS activates $\mathrm{p} 53$, which in turn transcribes a set of genes that inactivate ROS [29]. For example p53 transcribes a selected set of the sestrin genes, which produce proteins with a number of reduced cysteine residues (R-SH) that destroy ROS by reacting with it resulting in disulfide bonds [30]. Similarly an activated p53 induces the transcription of Parkin and GLS-2 each of which results in higher levels of reduced glutathione (G-SH) [27,28]. ROS reacts with G-SH producing the oxidized form of 
glutathione (G-S-S-G) and destroying ROS. The p53regulated gene, TIGAR, produces more glutathione by inhibiting the glycolytic enzyme phosphofructokinase, such that glucose is now shuttled into the pentose phosphate pathway and away from the glycolytic pathway [31]. The pentose phosphate pathway produces NADPH, which is required for generation of reduced glutathione. As discussed above the activated p53 protein shuts down the IGF-1/mTor pathway and the inactivity of TORC1 induces autophagy, which can include the destruction of defective mitochondria (mitophagy). Thus p53 can induce compounds and proteins that inactivate ROS and eliminate defective mitochondria. But p53 has other important effects on cellular ROS (Figure 2). p53 mediated cell death can result from the transcription of BAX, PUMA and NOXA which act at the mitochondria to release cytochrome c. Cytochrome $\mathrm{c}$ combines with the p53 regulated gene product APAF-1, which then activates caspases resulting in cell death by apoptosis [6-8]. ROS increases during apoptosis, and so a decreased expression of BAX and PUMA observed with a mutant p53 in cells not only blocks apoptosis but also decreases ROS[32]. Indeed an active p53 can also increase ROS. P53 induces ferrodoxin reductase and PIG3, which are part of ROSgenerating pathways [33], and represses Pdk2 resulting in strong ROS production by the electron transport chain [25]. And finally, it should be noted that in response to high ROS p53 can effect mitochondrial integrity directly, by changing its conformation and inserting into mitochondrial membranes, thereby opening a large pore that leads to necrosis [34]. This dual ability of wild type $\mathrm{p} 53$, to produce ROS inactivating functions under one condition and to induce ROS levels under different conditions provides a good example of the protective or destructive roles of the p53 protein. It is not clear how these dual roles are regulated nor is it clear what initiates

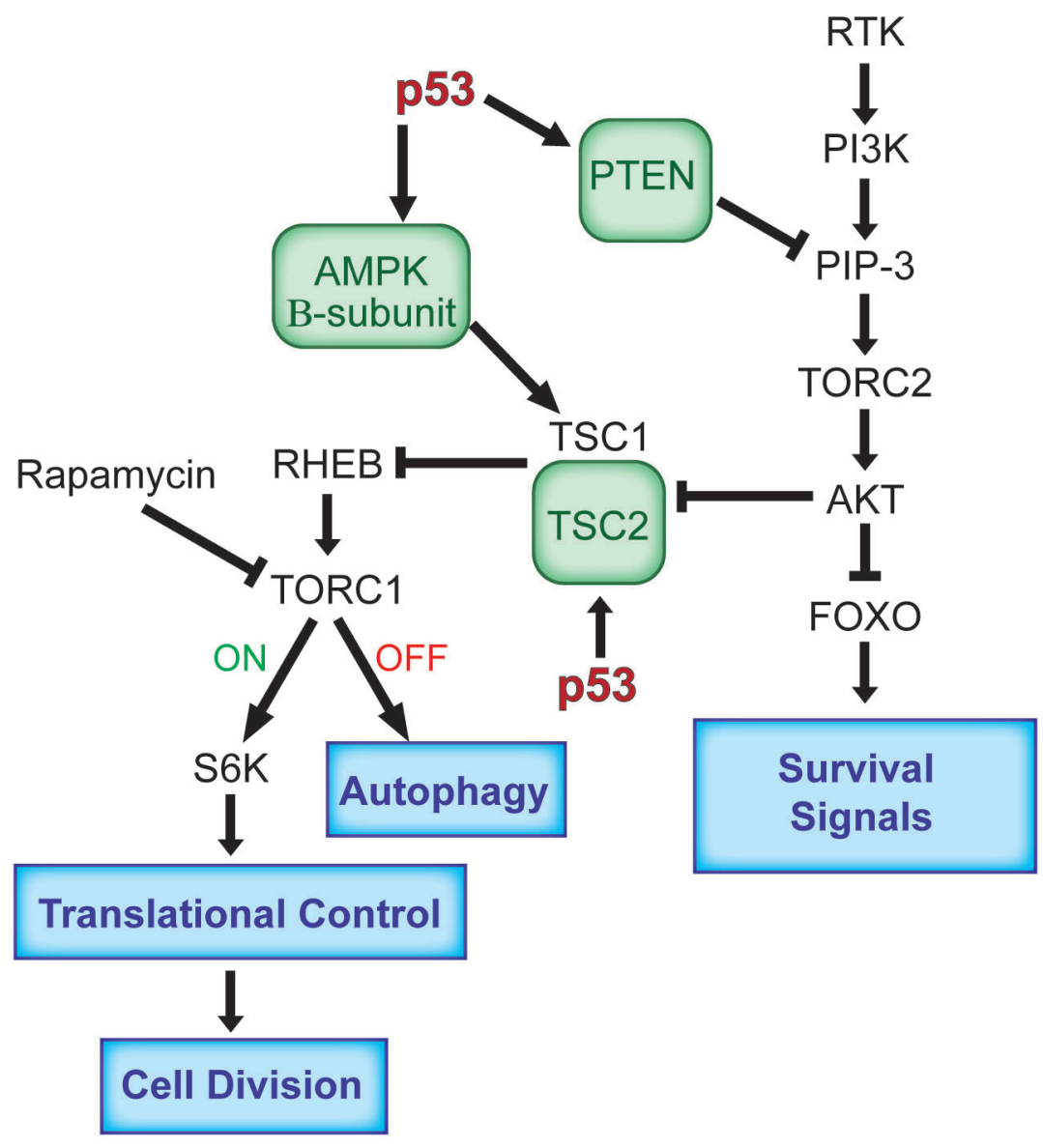

Figure 1: The antagonistic relationship between the p53 and the IGF-1/m Tor pathways. The activation of p53 in response to a lack of nutrient signals results in the enhanced transcription of Pten, TSC2 and AMPK (beta subunit), to block the functioning of the IGF$1 / \mathrm{m}$ Tor pathways in transformed cells. This leads to a decrease in cell growth, which also mediates an inhibition of proliferation through p53 activation. Under conditions of glucose starvation, inactive TORC-1 (OFF) starts the process of autophagy, while under ample glucose conditions active TORC-1 (ON) phosphorylates its substrates leading to the regulation of translation promoting cell growth and division. Abbreviations: AMPK, AMP activated protein kinase; FOXO, Forkhead Box O; mTOR, mammalian target of rapamycin; mTORC, mammalian target of rapamycin complex; PI3K, phosphatidylinositol-3 kinase; PIP3, phosphatidylinositol 3,4,5-trisphosphate; PTEN, phosphatase and tensin homologue; Rheb, Ras homolog enriched in brain; S6K, ribosomal protein S6 kinase; TSC1, TSC2, tuberosclerosis complex. 
these diverse responses.

\section{The Parkinson pathway responds to ROS:}

Over the past few years a number of genes have been identified whose mutant alleles have been shown to contribute to early onset Parkinson's Disease. The functions (at least in part) of four of these genes (PINK1, PARKIN, DJ-1 and LRRK-2) are to respond to the presence of ROS and eliminate defective mitochondria by mitophagy, reduce ROS levels and even kill cells that are damaged by ROS [35-40] (figure 2). In response to ROS the PTEN induced protein kinase (PINK-1) combines with the ubiquitin ligase Parkin and the complex translocates to the mitochondria [36,37]. Pink phosporylates Parkin which then polyubiquitinates proteins on the surface of the mitochondria initiating mitophagy in response to ROS production [37]. Similarly DJ-1 protein concentrations increase in response to ROS and it is translocated to mitochondria in a Pink-Parkin dependent fashion [39]. Based upon the structure of DJ-1 it is thought to function as a peroxidase inactivating ROS produced in mitochondria. Interestingly the oxidized DJ-1 cysteines are regenerated to reduced (R-SH) residues by glutathione, whose levels are increased by GLS-2 and Parkin, both p53 regulated genes (figure 2). A fourth Parkinsons gene, LRRK-2, is a protein kinase that, unlike Pink, Parkin and DJ-1, (which are recessive alleles resulting in Parkinsons Disease) acts as a dominant mutation responding to ROS by initiating programmed cell death [41]. There is a curious relationship between $\mathrm{p} 53$ and DJ-1. In cells with wild type p53, DJ-1 levels are low but respond to the presence of ROS by small increases in the DJ-1 protein concentration (2-3 fold). In transformed cells that have p53 mutations, the DJ-1 levels are commonly very high (30-100 fold increases). This suggests that $\mathrm{p} 53$ negatively regulates DJ-1 levels in non-transformed cells. However both transformation and p53 mutation is required to raise DJ-1 to very high levels in cells [42]. This means that DJ-1 is the dominant limitation on ROS levels in p53 mutant cancer cells, while p53 may take a leading role in normal cells with wild type p53. DJ-1 also has a curious relationship with PTEN another major tumor suppressor gene product. In a screen carried out in Drosophila (in the eye of Drosophila) DJ-1 was shown to be a suppressor of excessive PTEN activity [40]. These observations are consistent with the observation that DJ-1 can function as an oncogene and transform cells in culture along with other oncogenes [43]. These observations do not appear to be consistent with the claim that DJ-1 functions as a peroxidase at mitochondria. If DJ-1 is a peroxidase it should protect cells from ROS and reduce cellular damage while lowering the increased mutation rate observed with higher levels of ROS. This is expected for a tumor suppressor gene, not an oncogene.

\section{What can we conclude and what questions remain?}

The integration of some of the gene functions that lead to early onset Parkinsons disease when defective (Pink-1, Parkin, DJ-1 and LRRK-2) into the p53 and $\mathrm{PI} 3 \mathrm{~K} / \mathrm{mTor}$ pathways responding to ROS suggests a possible causation for at least some types of Parkinson's disease. Indeed T. Mak and D. Park and their colleagues have demonstrated using knock out mice that these gene functions reviewed here that are associated with mitochondria and ROS, may well play a role in neurons [38-39]. Why the dopaminergic neurons of the Substantia Nigra should be particularly susceptible to this type of cellular stress is unclear but some have speculated that these neurons have fewer mitochondria than other types of neurons so loss of some to ROS might result in a bigger problem for the cell, lead to ATP limitations and cell death at an earlier time. The relationship between the Parkinson pathway genes and p53 and IGF-1/mTor pathway brings up the question of whether p53 or LRRK-2 could be initiating cell death in these neurons? The possible role of ROS in Parkinson's Disease suggests the use of reducing agents such as $\mathrm{N}$-acetyl- cysteine for treatment by reducing ROS levels [44-45]. There have been clear positive associations between an increased risk of prostate cancer and melanoma in patients with Parkinson's Disease or in individuals who eventually developed Parkinson's Disease [46-47]. At the same time there is a lower risk for smoking related cancers of the lung and larynx in Parkinsons patients even taking into account the smoking habits of the group [48]. Whether this is a reflection of the cancer promoting roles of ROS in different tissues remains to be explored.

The role of Parkin in ROS reduction helps to explain why it is sometimes called a tumor suppressor gene and both alleles can be found in a mutant form in some cancers [49]. It also helps to explain its role in metabolic control of the Warburg effect and its ability to enhance glutathione levels in cells [28]. This is also consistent with the reasons why Parkin is a p53-regulated gene responding to ROS induced stress. It is interesting that mutations in genes that populate these three signal transduction pathways can result in cancers, neurodegenitive diseases and metabolic alterations supporting cell growth and division. This suggests that there are significant differences in the tissue specific uses of these pathways in different cell types resulting in diverse phenotypes depending upon the gene with a mutation in a pathway.

The role of $\mathrm{p} 53$ in regulating ROS can be demonstrated by the observation that cancers in p53 knockout mice can be delayed by the administration of $\mathrm{N}$-acetyl-cysteine [44]. This suggests that a mutation in the p53 gene leads to enhanced ROS, which in turn leads to more rapid development of cancers. P53 not only regulates ROS by sestrins, Parkin, GLS-2, TIGAR and by generating 
enhanced levels of reduced glutathione (R-SH), it can shut off TORC1 and 2 initiating mitophagy [50]. Interestingly two papers have recently appeared demonstrating that treatment of p53 knockout mice or heterozygous mice (as in Li-Fraumeni patients) with rapamycin, a drug that inhibits TORC1, can also slow the appearance of tumors in these mice [51-52]. The absence of (or lower levels of) p53 in p53 mutant mice relieves the break upon the TORC1 pathway and Rapamycin restores that break delaying the progression of mutations required to produce a cancer in either a knock out mouse or Li-Fraumeni (heterozygous) mice. This observation brings up the interesting possibility that treating Li-Fraumeni patients with either $\mathrm{N}$-acetylcysteine and/or Torc1 inhibitors might delay or reduce the number of tumors that develop in these patients over a lifetime. These observations are consistent with an important role for ROS in the development of cancers and the progression of cancers. This may especially be

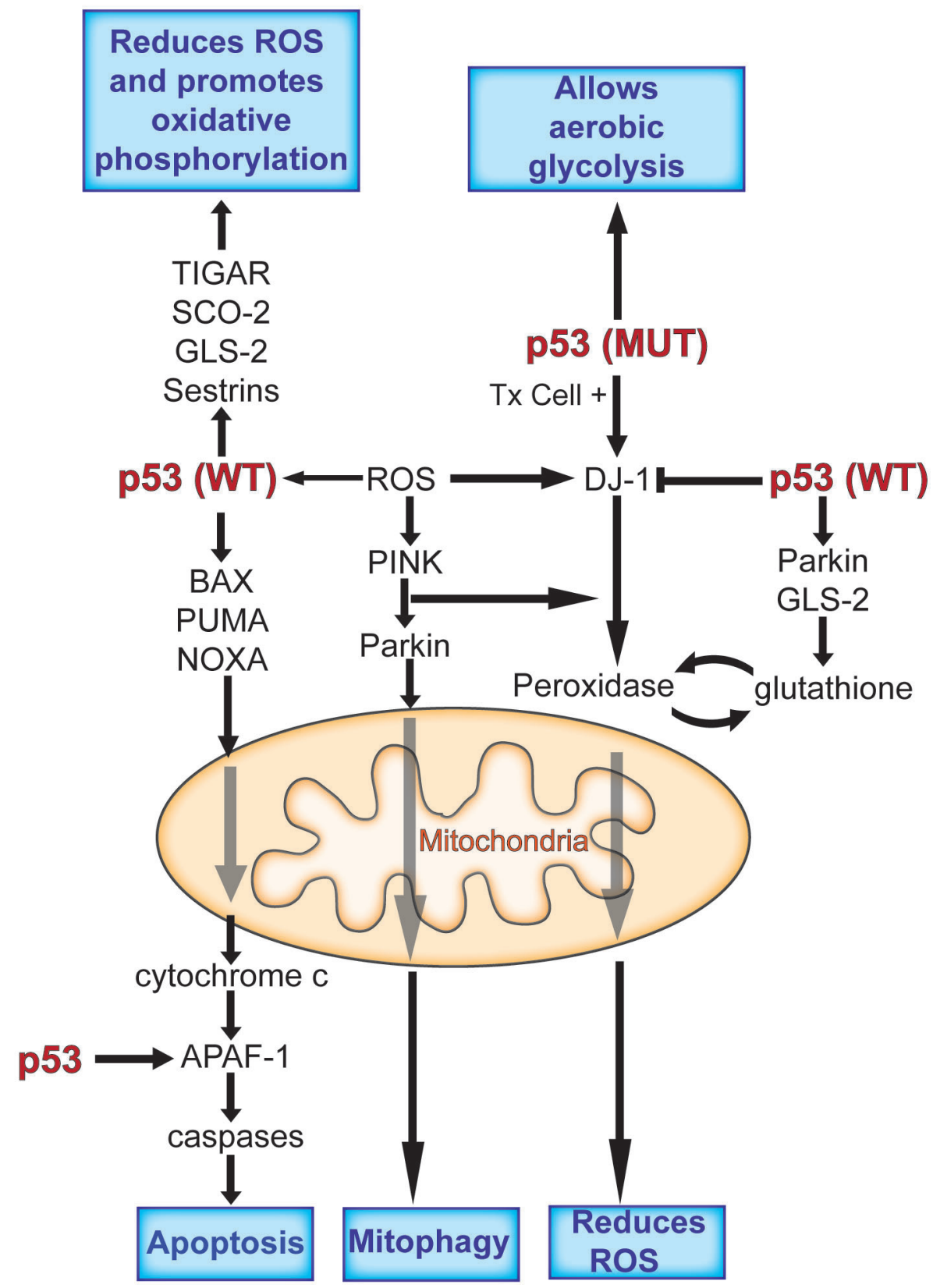

Figure 2: p53 functions in a complex network to mediate a cell's adaptation to stress. p53 is able to reduce the flux through the glycolytic pathway and increase oxidative phosphorylation, and in doing so opposes the Warburg effect. p53 is also able to regulate oxidative stress, through increasing it or decreasing it. It can play an antioxidant role and protect cells from high levels of ROS, promoting cell survival or a pro-oxidant activity that contributes to removal of a damaged or stressed cell. Abbreviations: APAF-1, apoptotic peptidase activating factor 1; BAX, BCL2-associated X protein; GLS-2, glutaminase 2; PINK, pten-induced putative kinase 1; PUMA, p53 upregulated modulator of apoptosis; ROS, reactive oxygen species; SCO2, synthesis of cytochrome c oxidase; TIGAR, TP53induced glycolysis and apoptosis regulator; Tx, transformed cell. 
the case in cancers that harbor p53 mutations. One of the reasons why cancers with p53 mutations often have a poor prognostic outcome could be because of high levels of ROS in the tumor cells. The implications for the diet and the type of drugs employed to treat cancer patients could be important and these concepts should at least be tested.

\section{ACKNOWLEDGEMENTS:}

The authors wish to acknowledge the work of T. Mak and D. Park and their colleagues (Joselin et al, 2012) who first described the roles of PINK, PARKIN and DJ-1 in the ROS pathway in fibroblasts and neurons and in knockout mice. This work was supported by grants from the Breast Cancer Foundation and NIH, NCI, PO1CA87497-12.

\section{REFERENCE}

1. Feng Z, Levine AJ. (2010) The regulation of energy metabolism and the IGF-1/mTOR pathways by the p53 protein. Trends Cell Biol. 2010; 20: 427-34.

2. Levine AJ, Puzio-Kuter A. (2010) The control of the metabolic switch in cancers by oncogenes and tumor suppressor genes. Science. 2010; 330: 1340-44.

3. Meek DW. (2009) Tumour suppression by p53: a role for the DNA damage response? Nat Rev Cancer. 2009; 9: 714723.

4. Hu W, Feng Z, Levine A.J. (2012) The Regulation of Multiple p53 Stress Responses are Mediated Through MDM-2. Genes Cancer. 2012; 3: 199-208.

5. Mirzayans R, Andrais B, ScottA , and Murray D. (2012) New Insights into p53 Signaling and Cancer Cell Response to DNA Damage: Implications for Cancer Therapy. J Biomed Biotechnol. 2012;2012:170325.

6. Robles AI, Bemmels NA, Foraker AB, Harris CC. (2001) APAF-1 Is a Transcriptional Target of p53 in DNA Damage-induced Apoptosis. Cancer Res. 2001; 61: 6660-4.

7. Li J, Lee B, Lee AS. (2006) Endoplasmic reticulum stressinduced apoptosis: multiple pathways and activation of $\mathrm{p} 53$ up-regulated modulator of apoptosis (PUMA) and NOXA by p53. J Biol Chem. 2006; 281: 7260-70.

8. Yee KS, Wilkinson S, James J, Ryan KM, Vousden KH. (2009) PUMA- and Bax-induced autophagy contributes to apoptosis. Cell Death Differ. 2009;16:1135-1145.

9. Bayascas JR, Alessi DR. Regulation of Akt/PKB Ser473 phosphorylation. (2005) Mol Cell. 2005;18:143-145.

10. Sarbassov DD, Guertin DA, Ali SM, Sabatini DM. Phosphorylation and regulation of Akt/PKB by the rictormTOR complex. Science. 2005; 307:1098-1101.

11. Scheid MP, Marignani PA, Woodgett JR. (2006) Multiple phosphoinositide 3-kinase-dependent steps in activation of protein kinase B. Mol Cell Biol. 2002;22:6247-6260.

12. Inoki $\mathrm{K}$, $\mathrm{Li} \mathrm{Y}$, Zhu $\mathrm{T}, \mathrm{Wu} \mathrm{J}$, Guan $\mathrm{KL}$. TSC2 is phosphorylated and inhibited by Akt and suppresses mTOR signalling. Nat Cell Biol. 2002;4:648-657.

13. Hannan KM, Brandenburger Y, Jenkins A, Sharkey K, Cavanaugh A, Rothblum L, Moss T, Poortinga G, McArthur GA, Pearson RB, Hannan RD. (2003) mTOR-dependent regulation of ribosomal gene transcription requires $\mathrm{S} 6 \mathrm{~K} 1$ and is mediated by phosphorylation of the carboxy-terminal activation domain of the nucleolar transcription factor UBF. Mol Cell Biol. 2003;23:8862-8877.

14. Holz MK, Ballif BA, Gygi SP, Blenis J. (2005) mTOR and S6K1 mediate assembly of the translation preinitiation complex through dynamic protein interchange and ordered phosphorylation events. Cell. 2005 a;123:569-580.

15. Holz MK, Blenis J. (2005) Identification of S6 kinase 1 as a novel mammalian target of rapamycin (mTOR)phosphorylating kinase. J Biol Chem. 2005 b;280:2608926093.

16. Warburg O, Posener K, Negelein E. 1924. Über den Stoffwechsel der Carcinomzelle. Biochem. Zeitschr. 1924;152:309-344.

17. Warburg O. (1956) On the origin of cancer cells. Science. 1956; 123: 309.

18. Shim H, Dolde C, Lewis BC, Wu CS, Dang G, Jungmann RA, Dalla-Favera R, Dang CV. c-Myc transactivation of LDH-A: implications for tumor metabolism and growth. Proc Natl Acad Sci U S A. 1997;94:6658-6663.

19. Semenza GL. Targeting HIF-1 for cancer therapy. Nat Rev Cancer. 2003;3:721-732.

20. Elstrom RL, Bauer DE, Buzzai M, Karnauskas R, Harris MH, Plas DR, Zhuang H, Cinalli RM, Alavi A, Rudin CM, Thompson CB. (2004) Akt stimulates aerobic glycolysis in cancer cells. Cancer Res. 2004; 64:3892-3899.

21. Plas DR, Thompson CB. (2005) Akt-dependent transformation: there is more to growth than just surviving. Oncogene. 2005;24:7435-7442.

22. Feng Z, Zhang H, Levine AJ, Jin S. (2005) The coordinate regulation of the $\mathrm{p} 53$ and $\mathrm{mTOR}$ pathways in cells. Proc Natl Acad Sci U S A. 2005;102:8204-8209.

23. Feng Z, Hu W, de Stanchina E, Teresky AK, Jin S, Lowe S, Levine AJ. (2007) The regulation of AMPK beta1, TSC2, and PTEN expression by p53: stress, cell and tissue specificity, and the role of these gene products in modulating the IGF-1-AKT-mTOR pathways. Cancer Res. 2007;67:3043-3053.

24. Stambolic V, MacPherson D, Sas D, Lin Y, Snow B, Jang Y, Benchimol S, Mak TW. Regulation of PTEN transcription by p53. Mol Cell. 2001;8:317-325.

25. Contractor T, Harris C (2012). p53 negatively regulates transcription of the pyruvate dehydrogenase kinase Pdk2. Cancer Res. 2012; 72:560-7.

26. Matoba S, Kang JG, Patino WD, Wragg A, Boehm M, Gavrilova O, Hurley PJ, Bunz F, Hwang PM. (2006) p53 regulates mitochondrial respiration. Science. 2006;312:1650-1653. 
27. Hu W, Zhang C, Wu R, Sun Y, Levine A, Feng Z. (2010) Glutaminase 2, a novel p53 target gene regulating energy metabolism and antioxidant function. Proc Natl Acad Sci USA. 2010; 107:7455-60.

28. Zhang $\mathrm{C}$, Lin $\mathrm{M}, \mathrm{Wu} \mathrm{R}$, Wang $\mathrm{X}$, Yang B, Levine AJ, Hu W, Feng Z. (2011) Parkin, a p53 target gene, mediates the role of p53 in glucose metabolism and the Warburg effect. Proc Natl Acad Sci USA. 2011; 108:16259-64.

29. Maillet A, Pervaiz S. (2012) Redox regulation of p53, redox effectors regulated by p53: a subtle balance. Antioxid Redox Signal. 2012; 16: 1285-94.

30. Budanov AV. (2011) Stress-responsive sestrins link p53 with redox regulation and mammalian target of rapamycin signaling. Antioxid Redox Signal. 2011; 15:1679-90.

31. Bensaad K, Tsuruta A, Selak MA, Calvo Vidal MN, Nakano K, Bartrons R, Gottlieb E, Vousden KH. (2006) TIGAR, a p53-Inducible Regulator of Glycolysis and Apoptosis. Cell. 2006; 126: 107-120.

32. Macip S, Igarashi M, Berggren P, Wu J, Lee SW, Aaronson SA (2003). Influence of induced reactive oxygen species in p53-mediated cell fate decisions. Mol Cell Biol. 2003; 23: 8576-85.

33. Polyak K, Xia Y, Zweier JL, Kinzler KW, Vogelstein B. (1997) A model for p53-induced apoptosis. Nature. 1997; 389: 300-5.

34. Vaseva AV, Marchenko ND, Ji K, Tsirka SE, Holzmann S, Moll UM (2012). P53 opens the mitochondrial transition pore to trigger necrosis. Cell. 2012;149: 1536-48.

35. Gasser T. (2007) Update on the genetics of Parkinson's disease. Mov Disord. 2007; 22: S343-50.

36. Narendra D., Tanaka A, Suen, D, Youle R. (2008) Parkin is recruited selectively to impaired mitochondria and promotes their autophagy, J. Cell Biol. 183, 795-803.

37. Chu C. (2010) Tickled PINK 2008; 1: Mitochondrial Homeostasis and Autophagy in Recessive Parkinsonism. Biochem Biophys. Acta; 1802: 20-28.

38. Rousseaux MW, Marcogliese PC, Qu D, Hewitt SJ, Seang S, Kim RH, Slack RS, Schlossmacher MG, Lagace DC, Mak TW, Park DS. (2012) Progressive Dopaminergic Cell Loss with unilateral to bilateral progression in a genetic model of Parkinson's Disease. Proc Natl Acad Sci U S A. 2012; 109: 15918-15923.

39. Joselin A.P, Hewitt SJ , Callaghan SM, Kim RH, ChungY, Mak T, Shen J , Slack RS, Park DS., (2012) ROSDependent regulation of Parkin and DJ-1 localization during oxidative stress in neurons. Hum Mol Genet. 2012; 21:4888-903

40. Kim RH, Peters M, Jang Y, Shi W, Pintilie M, Fletcher GC, DeLuca C, Liepa J, Zhou L, Snow B, Binari RC, Manoukian AS, Bray MR, Liu FF, Tsao MS, Mak TW. (2005) DJ-1, a novel regulator of the tumor suppressor PTEN. Cancer Cell. $2005 ; 7: 263-73$.

41. Iaccarino C, Crosio C, Vitale C, Sanna G, Carri MT, Barone P. (2007) Apoptotic mechanisms in mutant LRRK2-mediate cell death. Hum Mol Genet. 2007; 16:1319-1326.

42. Vasseur S, Afzal S, Tomasini R, Guillaumond F, TardicelLacombe J, Mak TW, Iovanna JL. (2012). Consequences of DJ-1 upregulation following p53 loss and cell transformation. Oncogene. 2012; 31: 664-70.

43. Nagakubo D, Taira T, Kitaura H, Ikeda 43. M, Tamai K, Iguchi-Ariga SM, Ariga H. (1997) DJ-1, a novel oncogene which transforms mouse NIH3t3 cells in cooperation with ras. Biochem Biophys Res Commun. 1997; 231:509-13.

44. Sablina A, Budanov A, Ilyinskaya G, Agapova, G, Krachenko J, Chumakov, p, 2005, the Anti-oxidant Function of the p53 Tumor Suppressor, Nat. Med, 11, 13061313.

45. Sun L, Gu L, Wand S, Yuan J, Yang H, Shu J, Zhang H. (2012). N-acetylcysteine protects against apoptosis through modulation of group I metabotropic glutamate receptor activity. PLoS One, 2012; 7:e32503.

46. Bertoni JM, Arlette JP, Fernandez HH, Fitzer-Attas C, Frei $\mathrm{K}$, Hassan MN, Isaacson SH, Lew MF, Molho E, Ondo WG, Phillips TJ, Singer C, Sutton JP, Wolf JE Jr; North American Parkinson's and Melanoma Survey Investigators. (2010) Increased melanoma risk in Parkinson disease: a prospective clinicopathological study. Arch Neurol. 2010; 67:347-52.

47. Inzelberg R, Rabey JM, Melamed E, Djaldetti R, Reches A, Badarny S, Hassin-Baer S, Cohen O, Trau H, AharonPeretz J, Milo R, Schwartz M, Huberman M, Gilead L, Barchana M, Liphshiz I, Fitzer-Attas C, Giladi N. (2011) High prevalence of malignant melanoma in Israeli patients with Parkinson's disease. J Neural Transm. 2011; 118:1199207.

48. Hernán MA, Takkouche B, Caamaño-Isorna F, GestalOtero JJ. (2002) A meta-analysis of coffee drinking, cigarette smoking, and the risk of Parkinson's disease. Annals of Neurology. 2002; 52: 276-84.

49. Veeriah S, Morris L, Solit D, Chan TA. (2010). The familial Parkinson disease gene PARK2 is a multisite tumor suppressor on chromosome 6q25.2-27 that regulates cyclin E. Cell Cycle. 2010; 9: 1451-2.

50. Vousden KH, Ryan KM. (2009). p53 and metabolism. Nat Rev Cancer. 2009; 9:691-700.

51. Komarova E, Antoch M, Novototskaya L, Chernova O, Paszkiewicz G, Leontieva O, Blagosklonny $\mathrm{M}$ and Gudkov A, (2012), rapamycin extends lifespan and delays tumorigenesis in heterozygous p53+/- mice. Aging (Albany NY). 2012; 4: 709-14.

52. Comas M, Toshkov I, Kuropatwinski K, Chernova O, Polinsky A, Blagosklonny M, Gudkov A, and Antoch M, (2012), New nanoformulation of rapamycin Rapatar extends lifespan in homozygous p53-/- mice by delaying carcinogenesis. Aging (Albany NY). 2012; 4: 715-22. 